\title{
Differences Between the Anthranilate-5- phosphoribosylpyrophosphate Phosphoribosyltransferases of Salmonella typhimurium Strains LT2 and LT7
}

\author{
By MARGARET DOOLEY,* ROBERT TORGET AND \\ ELIAS BALBINDER \\ Department of Biology, Syracuse University, Syracuse, New York, U.S.A., \\ and AMC Cancer Research Center and Hospital, Lakewood, \\ Colorado 80214, U.S.A.
}

(Received 6 September 1978)

\begin{abstract}
The anthranilate-5-phosphoribosylpyrophosphate phosphoribosyltransferases (PRT), coded by the second structural gene $(\operatorname{trp} B)$ of the tryptophan $(\operatorname{trp})$ operon in strains LT2 and LT7 of Salmonella typhimurium, differ from each other in a number of parameters. These include the apparent $K_{\mathrm{m}}$ values for their substrates anthranilic acid and 5-phosphoribosylpyrophosphate, thermostability, sensitivity to substrate inhibition by anthranilic acid, as well as end-product inhibition by tryptophan and specific activity. The PRT of strain LT7 further differs from that of strain LT2 in that its apparent $K_{\mathrm{m}}$ for 5-phosphoribosylpyrophosphate is three to seven times higher when associated with anthranilate synthase in the enzyme complex which catalyses the first two steps of tryptophan biosynthesis than in its free uncomplexed form, while the PRT of strain LT2 shows the same apparent $K_{\mathrm{m}}$ for this substrate in both its free and complexed forms. These results confirm and extend the finding of Stuttard (1975) that strains LT2 and LT7 differ genetically from each other at a single site within region II of the $\operatorname{trp} B$ gene.
\end{abstract}

\section{INTRODUCTION}

The enzyme complex which catalyses the first two steps in the biosynthesis of tryptophan has been extensively investigated in a variety of micro-organisms (for review, see Zalkin, 1973). In Salmonella typhimurium and other enteric bacteria this bifunctional complex consists of two monomers each of anthranilate synthase (EC 4.1.3.27; AS component 1 or AS-Col) and anthranilate-phosphoribosylpyrophosphate phosphoribosyltransferase (EC 2.4.2.18; PRT), the respective products of the $\operatorname{trp} A$ and $\operatorname{trp} B$ genes in $S$. typhimurium. Some of the properties of this complex are indicated in Fig. 1. Free AS-CoI can catalyse reaction 1:

$$
\text { Chorismate }+\mathrm{NH}_{3} \stackrel{\mathrm{Mg}^{2+}}{\longrightarrow} \text { Anthranilate }+ \text { Pyruvate }+\mathrm{H}_{2} \mathrm{O}
$$

In wild-type strains, AS-CoI is associated with PRT and in this complexed form it can utilize either $\mathrm{NH}_{3}$ or L-glutamine (Gln) as a substrate (reaction 2):

$$
\text { Chorismate }+\mathrm{Gln} \stackrel{\mathrm{Mg}^{2+}}{\longrightarrow} \text { Anthranilate }+ \text { Pyruvate }+ \text { L-Glutamate }+\mathrm{H}^{+}
$$

In this reaction, the amino-terminal $40 \%$ of the PRT sub-unit, specified by region I of $\operatorname{trpB}$ (Fig. 1), functions as a glutamine amidotransferase (GAT or AS component II,

* Present address: Department of Biochemistry and Biophysics, University of California, Davis, California 95616, U.S.A. 


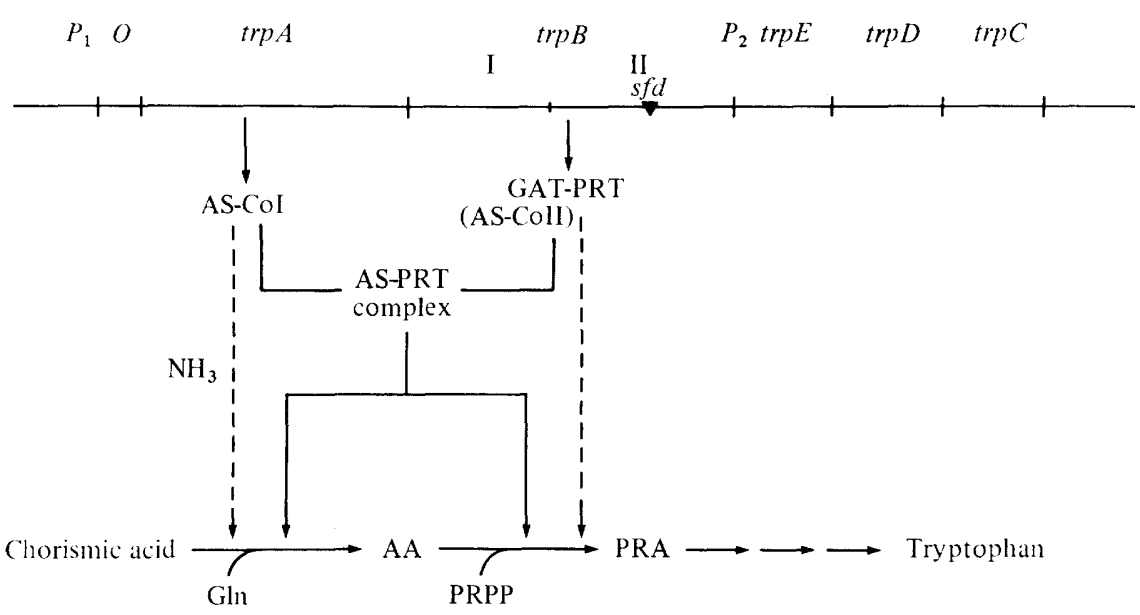

Fig. 1. AS-PRT complex of the trp operon of Salmonella typhimurium. The dashed lines indicate those reactions which can be carried out by each component of the complex in the dissociated state; the continuous lines indicate reactions carried out by each component as part of the complex. The position of the $s f d$ site (Stuttard, 1975) within $\operatorname{trpB}$ region II is indicated. Abbreviations: AA, anthranilic acid; AS-CoI, anthranilate synthase component I; GAT, glutamine amidotransferase; Gln, glutamine; PRA, $N$-(5'-phosphoribosyl)-anthranilate; PRPP, 5-phosphoribosylpyrophosphate; PRT, anthranilate-5-phosphoribosylpyrophosphate phosphoribosyltransferase.

AS-CoII) and is essential (Grieshaber \& Bauerle, 1972; Jackson \& Yanofsky, 1974). The carboxy-terminal $60 \%$ of the PRT sub-unit, specified by region II of $\operatorname{trp} B$ (Fig. 1), is not necessary for this reaction but catalyses reaction 3 , which is the second step in tryptophan biosynthesis.

$$
\begin{aligned}
& \text { Anthranilate + 5-Phosphoribosylpyrophosphate } \underset{\mathrm{Mg}^{2+}}{\longrightarrow} \\
& \qquad \text { - }\left(5^{\prime} \text {-Phosphoribosyl)-anthranilate }+\mathrm{PP}_{\mathrm{i}}\right.
\end{aligned}
$$

Tryptophan, the end-product of the pathway, is a feedback inhibitor of both AS and PRT activities of the complex, but the latter is inhibited to a lesser extent than the former (Henderson et al., 1970b; Nagano \& Zalkin, 1970; Zalkin \& Kling, 1968). Thus, inhibition of AS (but not PRT) activity can be bypassed by growing prototrophs in the presence of anthranilic acid. Stuttard (1975) has reported an interesting genetic difference between two wild-type strains of $S$. typhimurium, LT2 and LT7. He observed that when genetically derepressed prototrophs carrying a mutation in $\operatorname{trp} R$ (the gene for the $\operatorname{trp}$ repressor) were grown on minimal medium supplemented with anthranilic acid they secreted widely different amounts of tryptophan depending on the origin of their trp gene cluster. Those strains which possessed a trp operon derived from strain LT2 invariably excreted more tryptophan than those which possessed a trp operon derived from strain LT7. By a detailed genetic analysis, Stuttard traced this difference between strains LT2 and LT7 to a single site within region II of $\operatorname{trp} B$, the structural gene for the GAT-PRT polypeptide. He designated this site as $s f d$, for 'slow feeding determinant' (Fig. 1). Stuttard's observation clearly suggested that the AS-PRT complexes of strains LT2 and LT7 could have different properties resulting from a difference between their respective PRT components. The results presented in this report confirm this inference. 
Table 1. Substrains of Salmonella typhimurium. LT2 and LT7 used as sources of AS-PRT complexes and their free components

\begin{tabular}{|c|c|c|c|c|c|}
\hline Strain* & Genotype & $\begin{array}{l}\text { Origin of } \\
\text { trp region }\end{array}$ & $\begin{array}{c}\text { Genetic } \\
\text { background }\end{array}$ & $\begin{array}{l}\text { Type of } \\
\text { AS-PRT } \dagger\end{array}$ & Reference \\
\hline SD139 & $\operatorname{trpR} 1352$ & LT2 & LT2 & LT2-C & Stuttard (1975) \\
\hline SD140 & $\operatorname{trpR} 1352$ & LT7 & LT2 & LT7-C & Stuttard (1975) \\
\hline - & $\operatorname{trpE2} 2$ & LT2 & LT2 & LT2-C & Balbinder et al. (1970) \\
\hline - & $\operatorname{trp} A 703$ & LT2 & LT2 & LT2-PRT & Bauerle \& Margolin (1966) \\
\hline - & $\operatorname{trpBED} 164$ & LT2 & LT2 & LT2-AS & $\begin{array}{l}\text { Bauerle \& Margolin (1966); } \\
\text { Blume \& Balbinder (1966) }\end{array}$ \\
\hline SO114 & $\operatorname{trp} A 49 \operatorname{trp} A 512$ & LT7 & LT7 & LT7-PRT & Balbinder et al. (1968) \\
\hline - & $\operatorname{trpBEDC43}$ & LT7 & LT7 & LT7-AS & $\begin{array}{l}\text { Bauerle \& Margolin (1966); } \\
\text { Blume \& Balbinder (1966) }\end{array}$ \\
\hline
\end{tabular}

* All mutants without strain designations were originally isolated at the Cold Spring Harbor Laboratory under the direction of the late Dr M. Demerec. Strains SD139 and SD140 were kindly supplied by Dr C. Stuttard.

$\dagger$ C indicates AS-PRT native complex.

\section{METHODS}

Abbreviations. AA, Anthranilic acid; AS-CoI, anthranilate synthase component I; GAT, glutamine amidotransferase; PRPP, 5-phosphoribosylpyrophosphate; PRT, anthranilate-5-phosphoribosylpyrophosphate phosphoribosyltransferase; TS- $\beta, \beta$ sub-unit of tryptophan synthase.

Bacterial strains. The Salmonella typhimurium substrains used are described in Table 1. Substrain SD140 is a recombinant obtained by Stuttard which carries the $t r p$ genes of strain LT7 in the genetic background of strain LT2. Substrains SD140 and $\operatorname{trpE2}$, the latter carrying a mutation in the third gene of the trp operon, were routinely used to obtain native AS-PRT complexes from LT7 and LT2 origin, respectively. In a few experiments, the native LT2 complex was isolated from substrain SD139. No differences from $\operatorname{trp} E 2$ were observed. Substrains SO114 and $\operatorname{trpA703}$ have non-functional $\operatorname{trp} A$ genes and were the sources of free GAT-PRT polypeptide of LT7 and LT2 origin, respectively. The trp deletion mutant trpBEDC43 was used as a source of AS-CoI from LT7 and the deletion mutant trpBED164 as a source of AS-CoI from LT2. Genetic symbols follow the recommendations of Demerec et al. (1966).

Chemicals. Barium chorismate (converted to its potassium salt before use) and 5-phosphoribosylpyrophosphate (PRPP) were purchased from Sigma. The purity of PRPP was determined by measuring the amount of AA utilized in the presence of a limiting amount of PRPP, and the purity of chorismate was calculated from the amount of AA produced in the AS/Gln reaction in the presence of a limiting amount of chorismate. An excess of the AS-PRT complex was utilized in both cases. By this procedure the purity of the chorismate was found to be $50 \%$ and that of PRPP was $70 \%$. All other reagents were of the highest available purity and were used without further testing.

Bacterial growth. Bacteria used as sources of AS-PRT or the respective sub-units were grown in Vogel \& Bonner (1956) minimal medium supplemented with $0.25 \%(\mathrm{w} / \mathrm{v})$ glucose and $0.005 \%(\mathrm{w} / \mathrm{v})$ casein hydrolysate (Nutritional Biochemicals, Cleveland, Ohio, U.S.A.). The medium was prepared in 11 batches in 2.81 Fernbach flasks and inoculated with $1 \mathrm{ml}$ of an overnight culture in nutrient broth (Difco) of each strain. For prototrophic strains carrying the trpR1352 mutation, the minimal medium was not supplemented further. For tryptophan auxotrophs, the medium was supplemented with a limiting amount of L-tryptophan $\left(2 \mu \mathrm{g} \mathrm{ml}^{-1}\right)$ in order to derepress the trp operon enzymes. The bacteria were grown with aeration on a rotary shaker at $37^{\circ} \mathrm{C}$ for 15 to $18 \mathrm{~h}$.

Extract preparation. Bacteria were harvested by centrifugation $(6000 \mathrm{~g})$ and washed twice with $0 \cdot 1 \mathrm{M}-$ potassium phosphate buffer, $\mathrm{pH} 7 \cdot 8$, containing $1 \mathrm{~mm}$-2-mercaptoethanol. For some experiments, glycerol was added to this buffer to a concentration of $40 \%(\mathrm{v} / \mathrm{v})$. The bacteria were then resuspended in 3 vol. of the same buffer and broken by ultrasonic disruption in a Bronwill Biosonik III sonifier. Cell debris was removed by centrifugation at $29000 \mathrm{~g}$ for $70 \mathrm{~min}$.

Enzyme assays. PRT activity was measured fluorometrically by following the disappearance of AA according to the procedure of La Scolea \& Balbinder (1972). In some experiments (see Results and Discussion) the following modifications were introduced: (i) triethanolamine $/ \mathrm{HCl}$ was used at $\mathrm{pH} 7 \cdot 8$ instead of $\mathrm{pH} 7 \cdot 4$; (ii) the concentration of PRPP was $500 \mu \mathrm{M}$ rather than $20 \mu \mathrm{M}$. AS-GIn activity was measured by the method of Henderson et al. (1970a) and AS- $\mathrm{NH}_{3}$ activity was measured by the method of Zalkin \& Kling (1968) with the following modifications: (i) a final assay volume of $3 \mathrm{ml}$ instead of $1 \mathrm{ml}$ was used; (ii) $2-$ mercaptoethanol was substituted for thioglycerol. The $\beta$ sub-unit (TS- $\beta$ ) of tryptophan synthase, the enzyme 
Table 2. Specific activities in various reactions of the $A S-P R T$ complexes from strains LT2 and LT7

\begin{tabular}{|c|c|c|c|c|c|}
\hline \multirow[b]{3}{*}{ Origin } & \multirow{2}{*}{\multicolumn{2}{|c|}{ AS }} & \multicolumn{3}{|c|}{ Activity ratios } \\
\hline & & & & AS-NH & AS-Gln \\
\hline & Gln & $\mathrm{NH}_{3}$ & PRT* $^{*}$ & $\overline{\mathrm{AS}-\mathrm{Gln}}$ & $\overline{\text { PRT }}$ \\
\hline $\begin{array}{l}\text { LT2 } \\
\text { LT7 }\end{array}$ & $\begin{array}{l}7 \cdot 5 \\
3 \cdot 5\end{array}$ & $\begin{array}{r}15 \\
7\end{array}$ & $\begin{array}{c}18 \\
1.5\end{array}$ & $\begin{array}{l}2 \\
2\end{array}$ & $\begin{array}{l}0.42 \\
2 \cdot 3\end{array}$ \\
\hline
\end{tabular}

* PRT activities were assayed using $20 \mu \mathrm{M}-\mathrm{AA}$ and $500 \mu \mathrm{M}-\mathrm{PRPP}$ in triethanolamine $/ \mathrm{HCl}, \mathrm{pH} 7 \cdot 8$.

complex which catalyses the last step of tryptophan biosynthesis, was assayed as described by Smith \& Yanofsky (1962). Protein was determined by the method of Lowry et al. (1951). For the AS-PRT complex, one unit of enzyme activity is defined as the utilization (PRT) or production (AS) of $1 \mathrm{nmol} \mathrm{AA} \mathrm{min}{ }^{-1}$. One unit of TS- $\beta$ activity is defined as the utilization of $0 \cdot 1 \mu \mathrm{mol}$ indole $(20 \mathrm{~min})^{-1}$. Specific activity is defined as enzyme units ( $\mathrm{mg}$ protein) ${ }^{-1}$.

In vitro complexing of $A S$ and PRT. Uncomplexed AS-CoI and GAT-PRT were complexed in vitro by the method of Yanofsky et al. (1971). In experiments to determine the properties of in vitro complexed PRT, a previously determined excess of AS was added to a fixed number of units of free PRT and complex formation was confirmed by monitoring AS-Gln activity.

\section{RESULTS AND DISCUSSION}

Table 2 shows the specific activities in various reactions of the native AS-PRT complexes from strains LT2 and LT7. These AS-PRT complexes were obtained from substrains SD139 and SD140, both of which carry the mutation trpR1352 (Table 1) and are genetically derepressed. Assays of TS- $\beta$, the product of $\operatorname{tr} p D$ (the fourth structural gene of the $\operatorname{trp}$ operon), showed that both strains contained identical levels of this enzyme sub-unit and were, as expected, equally derepressed for the $\operatorname{tr} p$ operon. Table 2 shows that while there was only a small difference (about twofold) between the AS activities of each complex, there was a very dramatic difference between the respective PRT activities. At standard PRPP concentrations $(20 \mu \mathrm{M})$ no PRT activity could be detected for the LT7 enzyme complex while the LT2 enzyme complex showed a specific activity of 9.4. Measurable PRT activity for the LT7 complex was obtained by increasing the PRPP concentration to $500 \mu \mathrm{M}$, but even under these conditions the strain LT7 complex showed only about one-tenth of the specific activity of its LT2 counterpart (Table 2). The low PRT activity shown by the LT7 enzyme complex was not due to decreased synthesis of the strain LT7 GAT-PRT polypeptide, since the AS- $\mathrm{NH}_{3} / \mathrm{AS}-\mathrm{Gln}$ activity ratios were the same in both strains (Table 2) showing that both contained equal levels of GAT (AS-CoII). Furthermore, if a decreased amount of the GAT-PRT polypeptide was responsible for the low level of PRT activity of the LT7 enzyme complex, we would expect the same AS-Gln/PRT activity ratio for this complex as for the one from strain LT2. However, this ratio is about sixfold higher for the LT7 enzyme complex than for the LT2 complex (Table 2). The fact that substrains SD139 and SD140 were equally derepressed for TS- $\beta$ is further evidence against differences in amount of enzyme between the two strains, since the enzymes of the trp operon are known to derepress as a unit (Blume et al., 1968). The difference is, then, a qualitative one, the PRT of strain LT7 being inherently less active than that of strain LT2 in carrying out reaction 3 (see Introduction). This is consistent with Stuttard's (1975) location of the $s f d$ site within region II of the $\operatorname{trp} B$ gene, which codes for the portion of the GAT-PRT polypeptide responsible for the PRT reaction (Fig. 1).

We have mentioned that the PRT of strain LT7 required 25 times more PRPP than that of strain LT2 to show detectable activity in the PRT reaction. This suggests that the enzyme of strain LT7 has a higher $K_{\mathrm{m}}$ for this substrate than that of strain LT2. Table 3 shows some 
Table 3. Apparent $K_{\mathrm{m}}$ values for $A A$ and PRPP and substrate inhibition by $A A$ of complexed and free PRT from strains LT2 and LT7

\begin{tabular}{|c|c|c|c|}
\hline \multirow[b]{2}{*}{ Type of PRT* } & \multicolumn{2}{|c|}{ Apparent $K_{\mathrm{m}} \dagger\left(\mu_{\mathrm{M}}\right)$} & \multirow{2}{*}{$\frac{\text { Activity }(20 \mu \mathrm{M}-\mathrm{AA})}{\text { Activity }(5 \mu \mathrm{M}-\mathrm{AA})}$} \\
\hline & AA & PRPP & \\
\hline LT2-C & 10 & $9 \cdot 1$ & $1 \cdot 7$ \\
\hline LT2-F & $7 \cdot 4$ & $8 \cdot 5$ & $1 \cdot 6$ \\
\hline LT7-C & $0 \cdot 30$ & 47 & 0.7 \\
\hline LT7-F & $0 \cdot 14$ & $7 \cdot 2$ & $0 \cdot 6$ \\
\hline
\end{tabular}

* C, Complexed; F, free.

$\dagger$ The apparent $K_{\mathrm{m}}$ values for AA were determined with $500 \mu \mathrm{M}$-PRPP and the apparent $K_{\mathrm{m}}$ values for PRPP were determined with $20 \mu \mathrm{M}-\mathrm{AA}$; all assays were done in triethanolamine/ $\mathrm{HCl}, \mathrm{pH} 7 \cdot 8$.

Table 4. Apparent $K_{\mathrm{m}}$ values $(\mu \mathrm{M})$ for PRPP of uncomplexed and in vitro complexed $P R T S$

$\begin{array}{ccccc}\begin{array}{c}\text { AA concn } \\ (\mu \mathrm{M})\end{array} & \text { LT2-F } & \text { LT2-C } & \text { LT7-F } & \text { LT7-C } \\ 1 & & & & \\ 5 & \text { ND } & \text { ND } & 6 \cdot 7 & 10 \\ 20 & 5 & 5 \cdot 7 & 22 & 67 \\ & 9 \cdot 1 & 11 \cdot 1 & \text { ND } & \text { ND }\end{array}$

ND, Not determined. $\quad$ C, Complexed; F, free.

kinetic constants for complexed and free PRT from LT2 and LT7. The $K_{\mathrm{m}}$ values for AA and PRPP for the LT2 enzyme are in good agreement with published results (Henderson et $a l ., 1970 b$ ) and are substantially identical for both forms of the enzyme. The apparent $K_{\mathrm{m}}$ values for AA were 25- to 70-fold lower for strain LT7 than for strain LT2, both forms of the enzyme being identical in this respect. In contrast, the apparent $K_{\mathrm{m}}$ values for PRPP differed in the case of the PRT of strain LT7 depending on whether the enzyme was free or complexed, with that of the complexed PRT being about sevenfold higher than that of the uncomplexed enzyme. The latter showed a $K_{\mathrm{m}}$ for PRPP similar to that of the PRT of strain LT2. Table 3 (column 4) also points to another difference between the PRTs of strains LT2 and LT7. The LT7 enzyme, either complexed or free, appeared to be susceptible to substrate inhibition by AA at concentrations of this substrate which were not inhibitory to the PRT of strain LT2. This inhibition is reflected in the activity of PRT at $20 \mu \mathrm{M}-\mathrm{AA}$ relative to that at $5 \mu \mathrm{M}-\mathrm{AA}$. Although these ratios are identical for the complexed and free PRT of strain LT7, it is possible that some differences in sensitivity exist in vivo. Substrate inhibition by AA has also been observed with the AS-PRT complex of strain LT2 and it appears to start at about $30 \mu \mathrm{M}$-AA (P. Robison \& T. Grove, personal communication).

Stuttard (1975) found that constitutive prototrophs carrying the trp operon of strain LT2 excreted more tryptophan, as determined by feeding tests on anthranilate-supplemented minimal medium, than similar substrains carrying the trp operon of strain LT7, except when the latter had a deletion in the $\operatorname{trp} A$ gene, in which case no difference in feeding was detected. This observation shows that the PRT of strain LT7 must be aggregated with AS-CoI for reduced tryptophan synthesis to occur, and could be explained by the difference in apparent $K_{\mathrm{m}}$ for PRPP between the free and complexed forms of the PRT of strain LT7 (Table 3). If this difference in $K_{\mathrm{m}}$ is real, we can predict that if free PRT of strain LT7 were allowed to complex with AS-CoI its $K_{\mathrm{m}}$ for PRPP would increase. The results of such experiments, where free PRTs of LT2 and LT7 origin were allowed to complex in vitro with their respective AS-CoI sub-units, are shown in Table 4. At a concentration of $5 \mu \mathrm{M}-\mathrm{AA}$, LT7 PRT 
showed a threefold increase in apparent $K_{\mathrm{m}}$ for its substrate PRPP after it had entered into a complex with AS-CoI, while no change was seen for LT2 PRT. However, when the $K_{\mathrm{m}}$ for PRPP was measured at $1 \mu \mathrm{M}$-AA, a concentration equivalent to three times the $K_{\mathrm{m}}$ for this substrate, the change in $K_{\mathrm{m}}$ for PRPP was hardly noticeable. From these results it appears that two conditions must exist for a detectable increase in the $K_{\mathrm{m}}$ for PRPP of strain LT7 PRT: (i) the PRT must be complexed with AS-CoI and (ii) a relatively high concentration of AA (capable of producing substrate inhibition) must be present. The results given in Table 3 were determined with $20 \mu \mathrm{M}$-AA, which is a 70 -fold excess of this substrate over its $K_{\mathrm{m}}$ for strain LT7 PRT (about $0.3 \mu \mathrm{M}$ ) and, under these conditions, the observed difference in $K_{\mathrm{m}}$ for PRPP between the free and complexed forms of strain LT7 PRT was about sevenfold. Other systems where the $K_{\mathrm{m}}$ for a substrate can change depending on whether an enzyme sub-unit is complexed or free are known. For example, the $K_{\mathrm{m}}$ for indoleglycerolphosphate of the $\alpha$ sub-unit of Escherichia coli tryptophan synthase differs depending on whether this sub-unit is free $(0.47 \mathrm{~mm})$ or complexed with $\beta 2(0.05 \mathrm{~mm})$ (Creighton, 1970; Hardman \& Yanofsky, 1965). For the enzyme aspartate transcarbamylase, the concentration of aspartate at which the enzyme is half-saturated by substrate doubles following treatment with agents which lead to the dissociation of the enzyme into catalytic and regulatory sub-units (Gerhart \& Pardee, 1962). Our observations with PRT show that the ability to undergo a $K_{\mathrm{m}}$ change upon complexing depends on the origin of this enzyme component and is, as Stuttard (1975) has shown, genetically determined.

Another possible explanation for the feeding patterns observed by Stuttard (1975) would be that tryptophan inhibits PRT activity to a larger extent in the LT7 than in the LT2 AS-PRT complex; this difference would be eliminated by deletion of the structural gene for AS-CoI, since free PRT is not as susceptible as complexed PRT to inhibition by tryptophan (Henderson et al., 1970b). However, a comparison of tryptophan inhibition of PRT activity in LT2 and LT7 AS-PRT complexes did not support this explanation. The PRT activity of the AS-PRT complex of strain LT2 was always inhibited to the same extent, between 60 and $70 \%$, under a variety of substrate concentrations. The extent of inhibition of PRT activity in the strain LT7 complex varied depending on the AA concentration, but it was always much lower than that shown by the strain LT2 enzyme. For example, at $1 \mu \mathrm{M}-\mathrm{AA}$ inhibition was $29 \%$, and at $5 \mu \mathrm{M}$-AA it was $9 \%$. Thus, the PRT in the AS-PRT complex of strain LT7 is less, rather than more, susceptible to inhibition by tryptophan than that in the strain LT2 complex. We conclude that our results confirm the requirement for AS-PRT aggregation and show that this is not due to any relatively greater increase in end-product inhibition of aggregated strain LT7 PRT or to any reduction in the amount of GAT-PRT polypeptide produced by this strain, but can be explained by the increase in apparent $K_{\mathrm{m}}$ for PRPP undergone by the strain LT7 PRT upon aggregation with AS-CoI.

The PRTs of strains LT2 and LT7 also differed in their thermostability. When incubated in $40 \%$ glycerol, the PRT activity of the LT7 AS-PRT complex had similar stability to that of strain LT2, but the activity of the free PRT of strain LT7 was much less stable than that of its strain LT2 counterpart (Fig. 2). In the absence of glycerol, the PRT activity of the LT7 AS-PRT complex was inactivated more rapidly than that of the LT2 complex; after $8 \mathrm{~min}$ at $40{ }^{\circ} \mathrm{C}, 90 \%$ of the activity of the strain LT7 PRT was lost compared with only $10 \%$ for the strain LT2 PRT.

Comparative studies similar to those described for the PRT components of each complex were carried out for their AS-CoI components. No major differences in the apparent $K_{\mathrm{m}}$ values for the substrates chorismate and glutamine were observed between the AS-CoI components of the LT2 and LT7 AS-PRT complexes (Table 5). Also, both AS-CoI subunits showed the same thermostability. The only difference we detected between them is shown in Table 5 (column 4); the AS of strain LT7 appeared to be somewhat more sensitive to inhibition by tryptophan than did the AS of strain LT2. This could explain Stuttard's observation (1975) that repressible prototrophs carrying the AS-PRT complex of strain 


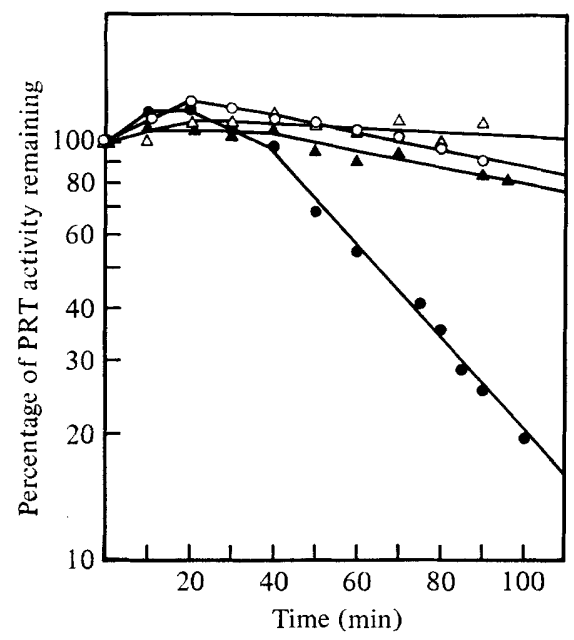

Fig. 2. Heat inactivation of PRT in the presence of $40 \%(\mathrm{v} / \mathrm{v})$ glycerol: $\triangle$, LT2, complexed PRT; $\Delta$, LT2, free PRT; $\bigcirc$, LT7, complexed PRT; 0, LT7, free PRT. At time zero, 2 ml extract were added to a pre-warmed test-tube at $47^{\circ} \mathrm{C}$; samples were removed at the times indicated and immediately assayed using $20 \mu \mathrm{M}-\mathrm{AA}, 500 \mu \mathrm{M}$-PRPP and triethanolamine $/ \mathrm{HCl}, \mathrm{pH} 7 \cdot 8$.

Table 5. Characteristics of AS from LT2 and LT7 strains

$\begin{array}{lccc}\begin{array}{c}\text { Derivation } \\ \text { of AS* }\end{array} & \overbrace{\text { Chor }}^{\text {Apparent }} & K_{\mathrm{m}} \dagger(\mu \mathrm{M}) & \begin{array}{c}\text { Percentage } \\ \text { inhibition }\end{array} \\ \text { LT2-C } & 2 \cdot 2 & 600 & \text { at } 125 \mu_{\mathrm{M}-T r p} \\ \text { LT7-C } & 5 \cdot 3 & 600 & 45 \\ & & \end{array}$

* C, Complexed.

$\uparrow$ All assays contained standard concentrations of the non-varied substrate. Chor, Chorismate; Gin, glutamine.

LT7 are more sensitive to growth inhibition by 5-methyltryptophan than similar strains carrying the AS-PRT complex of strain LT2, since 5-methyltryptophan can inhibit AS activity as well as repress the $\operatorname{trp}$ operon (Balbinder et al., 1970). We have not determined whether this represents an inherent difference between the AS-CoI polypeptides of the two strains or whether it is the result of a conformational effect of the PRT of strain LT7 on its AS-CoI.

Our results so far clearly show that PRT alone is responsible for most of the differences observed between the AS-PRT complexes of strains LT2 and LT7. On the basis of the activity ratios of AS-Gln/PRT for the wild-type native complexes (Table 2), we can predict that a constant number of units of strain LT7 PRT would have more GAT (AS-CoII) activity than an equal number of units of strain LT2 PRT. In vitro complexing of AS-CoI and GAT-PRT from strains LT2 and LT7 confirmed this prediction: the AS-GIn/PRT ratios of LT2 GAT-PRT were 0.2 and 0.3 when complexed, respectively, with AS-CoI of LT2 and LT7 origin, while the LT7 GAT-PRT showed ratios of 1.8 and 1.4 in parallel experiments. Thus, the ratios of AS-Gln/PRT activities are similar to those obtained with native AS-PRT complexes (Table 2), and are determined exclusively by the GAT-PRT component of the complex. The heat inactivation profiles for the PRT activities of the various in vitro complexes were typical of the PRT component and unaffected by the AS-CoI sub-unit participating in the complex. They were, in all respects, identical to those obtained with the native complexes. 
In conclusion, we have shown that the PRT sub-units of the AS-PRT enzyme complexes from strains LT2 and LT7 of Salmonella typhimurium differ from each other in several respects. These include their apparent $K_{\mathrm{m}}$. values for various substrates, thermostability, sensitivity to substrate inhibition as well as end-product inhibition by tryptophan, and specific activity. The differences are limited to that portion of the GAT-PRT sub-unit which participates in the PRT reaction, i.e. the carboxy-terminal $60 \%$ of the polypeptide. No major differences were detected which implicated the portion of the GAT-PRT sub-unit participating in the AS-Gln reaction (GAT or AS-CoII, corresponding to the $N$-terminal $40 \%$ of the PRT polypeptide), or the AS-CoI sub-units of the complexes. The only possible exception to this general observation is that the AS-PRT complex from strain LT7 is more susceptible to end-product inhibition by tryptophan in the AS-Gln reaction than the complex of strain LT2 (Table 5). Our results are consistent with the finding of Stuttard (1975) that a genetic difference at a single site within $\operatorname{trp} B$-region II exists between strains LT2 and LT7. It is possible that this difference at the gene level between the two strains is reflected in a single amino acid difference between their PRT moieties, and this can have large conformational effects. There is precedent for this situation. There have been reports of single site mutations in the structural gene for AS-CoI affecting several characteristics of both components of the AS-PRT complex and these were also interpreted as conformational changes (Cordaro et al., 1968; Pabst et al., 1973; Robison \& Levy, 1976).

The findings we report in this paper raise the question of whether mutations which have such a drastic effect on the properties of a biosynthetic enzyme will affect the survival of strains which carry them. It seems that they do not have any noticeable effect on survival, at least under natural conditions where biosynthetic enzymes such as those needed for tryptophan biosynthesis are probably repressed. The difference between the repressed and derepressed levels of the AS-PRT complex in S. typhimurium is approximately 100- to 150fold (Balbinder et al., 1968; Bauerle \& Margolin, 1967; Blume et al., 1968). Under repressing conditions there is very little enzyme present and the relative concentration of PRPP may be sufficient to allow the PRT reaction to proceed at a satisfactory rate for the cells in spite of the low affinity of the complexed PRT of strain LT7 for that substrate. It is also possible, since PRPP is a substrate for enzymes catalysing early steps of other biosynthetic pathways (histidine, purines), that the $K_{\mathrm{m}}$ values for PRPP of these enzymes are lower in strain LT7 than in strain LT2 to compensate for the elevated $K_{\mathrm{m}}$ shown by the strain LT7 PRT in its complexed form.

We wish to thank Drs H. R. Levy, T. H. Grove and P. Robison for their expert advice and Drs Levy and C. Stuttard for their comments and suggestions on the manuscript. This work was supported by grant GM 19839 from the U.S. Public Health Service, and grant GB 41489 of the National Science Foundation. Abstracted in part from the Ph.D. dissertation of Margaret Dooley.

\section{REFERENCES}

Balbinder, E., Blume, A., Weber, A. \& TAmaKi, H. (1968). Polar and antipolar mutants in the tryptophan operon of Salmonella typhimurium. Journal of Bacteriology 95, 2217-2229.

Balbinder, E., Callahan, R., McCann, P. P., Cordaro, J. C., Weber, A. R., Smith, A. M. \& Angelosanto, F. (1970). Regulatory mutants of the tryptophan operon of Salmonella typhimurium. Genetics 66, 31-53.

Bauerle, R. H. \& Margolin, P. (1966). A multifunctional enzyme complex in the tryptophan pathway of Salmonella typhimurium: comparison of polarity and pseudopolarity mutations. Cold
Spring Harbor Symposia on Quantitative Biology 31, 203-214.

Bauerle, R. H. \& Margolin, P. (1967). Evidence for two sites for initiation of gene expression in the tryptophan operon of Salmonella typhimurium. Journal of Molecular Biology 26, 423-436.

Blume, A. J. \& Balbinder, E. (1966). The tryptophan operon of Salmonella typhimurium. Fine structure analysis by deletion mapping and abortive transduction. Genetics 53, 577592.

Blume, A. J., Weber, A. \& Balbinder, E. (1968). Analysis of polar and nonpolar tryptophan 
mutants by derepression kinetics. Journal of Bacteriology 95, 2230-2241.

Cordaro, J. C., Levy, H. R. \& Balbinder, E. (1968). Product inhibition of anthranilate synthetase in Salmonella typhimurium. Biochemical and Biophysical Research Communications 33, 183-189.

Creighton, T. E. (1970). A steady-state kinetic investigation of the reaction mechanism of the tryptophan synthetase of Escherichia coli. European Journal of Biochemistry 13, 1-10.

Demerec, M., Adelberg, E. A., Clark, A. J. \& Hartman, P. E. (1966). A proposal for a uniform nomenclature in bacterial genetics. Genetics 54, 61-76.

Gerhart, J. C. \& Pardee, A. B. (1962). The enzymology of control by feedback inhibition. Journal of Biological Chemistry 237, 891-896.

Grieshaber, M. \& Bauerle, R. (1972). Structure and evolution of a bifunctional enzyme of the tryptophan operon. Nature New Biology 236, 232-235.

Hardman, J. K. \& Yanofsky, C. (1965). Studies on the active site of the $A$ protein subunit of the Escherichia coli tryptophan synthetase. Journal of Biological Chemistry 240, 725-732.

Henderson, E. J., Nagano, H., Zalkin, H. \& Hwang, L. H. (1970a). The anthranilate synthetase-anthranilate 5-phosphoribosylpyrophosphate phosphoribosyltransferase aggregate. Purification of the aggregate and regulatory properties of anthranilate synthetase. Journal of Biological Chemistry 245, 1416-1423.

Henderson, E. J., Zalkin, H. \& Hwang, L. H. $(1970 b)$. The anthranilate synthetase-anthranilate 5-phosphoribosylpyrophosphate phosphoribosyltransferase aggregate. Catalytic and regulatory properties of aggregated and unaggregated forms of anthranilate 5-phosphoribosylpyrophosphate phosphoribosyltransferase. Journal of Biological Chemistry 245, 1424-1431.

JACKSON, E. N. \& YANOFSKY, C. (1974). Localization of two functions of phosphoribosyl anthranilate transferase of Escherichia coli to distinct regions of the polypeptide chain. Journal of Bacteriology 117, 502-508.
La. Scolea, L. J. \& Balbinder, E. (1972). Restoration of phosphoribosyltransferase activity by partially deleting the $\operatorname{tr} p B$ gene in the tryptophan operon of Salmonella typhimurium. Journal of Bacteriology 112, 877-885.

Lowry, O. H., Rosebrough, N. J., FARr, A. L. \& RANDALL, R. J. (1951). Protein measurement with the Folin phenol reagent. Journal of Biological Chemistry 193, 265-275.

Nagano, H. \& Zalkin, H. (1970). Some physicochemical properties of anthranilate synthetase component I from Salmonella typhimurium. Journal of Biological Chemistry 245, 3097-3103.

Pabst, M. J., Kuhn, J. C. \& Somerville, R. L. (1973). Feedback regulation in the anthranilate aggregate from wild type and mutant strains of Escherichia coli. Journal of Biological Chemistry 248, 901-914.

Robison, P. D. \& LeVy, H. R. (1976). Metal ion requirement and tryptophan inhibition by normal and variant anthranilate synthetase-anthranilate5-phosphoribosylpyrophosphate phosphoribosyltransferases from Salmonella typhimurium. Biochimica et biophysica acta 445, 475-485.

Smith, O. H. \& YANOFSKY, C. (1962). Enzymes involved in the biosynthesis of tryptophan. Methods in Enzymology 5, 794-806.

StutTard, C. (1975). Tryptophan biosynthesis in Salmonella typhimurium: location in $\operatorname{trp} B$ of a genetic difference between strains LT2 and LT7. Journal of Bacteriology 123, 878-887.

VOGEL, H. J. \& BONNER, D. (1956). Acetylornithinase of Escherichia coli: partial purification and some properties. Journal of Biological Chemistry 218, 97-106.

YANOFSKY, C., HoRn, V., BonNer, M. \& STASIOWSKI, S. (1971). Polarity and enzyme functions in mutants for the first three genes of the tryptophan operon of Escherichia coli. Genetics 69, 409-433.

ZALKIN, H. (1973). Anthranilate synthetase. Advances in Enzymology 38, 1-39.

ZALKIN, H. \& KLING, D. (1968). Anthranilate synthetase - purification and properties of component I from Salmonella typhimurium. Biochemistry 7, 3566-3573. 